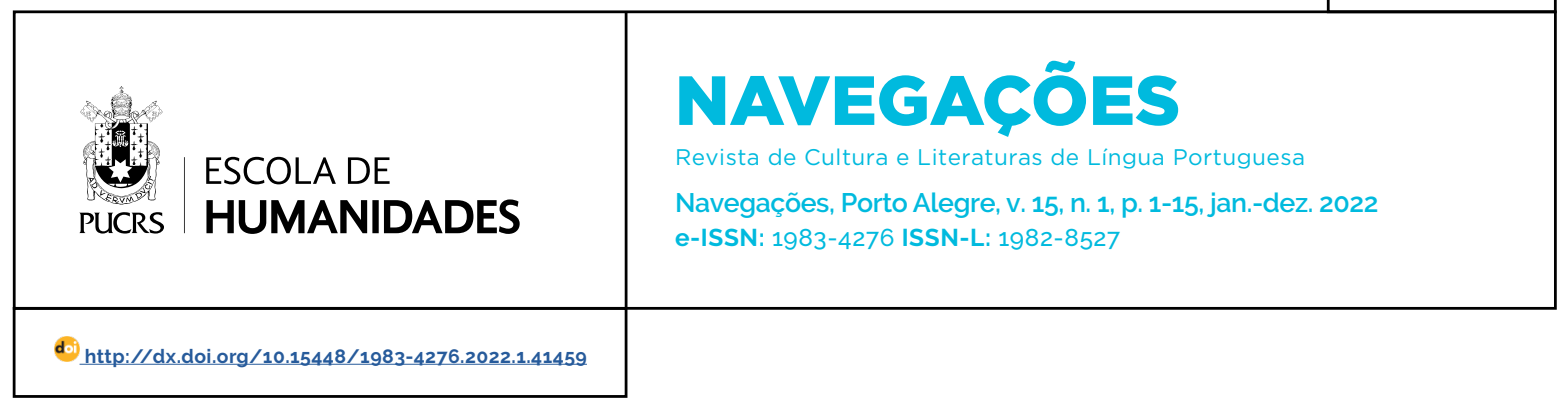

SEÇÃO: ENSAIOS

\title{
Mei-Lai, a menina mestiça do porto interior de Macau, em "A-Chan, a tancareira" (1950), de Henrique de Senna Fernandes (1923-2010)
}

Mei-lai, the mixed race little girl from the interior porto of Macao, in "A-Chan, a tancareira" (1950), de Henrique de Senna Fernandes (1923-2010)

\section{Denise Rocha ${ }^{1}$ \\ orcid.org/0000-0003-3906-2957 rocha.denise57@gmail.com}

Recebido em: 4 ago. 2021. Aprovado em: 29 set. 2021 Publicado em: 8 mar. 2022.
Resumo: O objetivo desse estudo é analisar no conto "A-Chan, a tancareira" (1950), de Henrique de Senna Fernandes (1923-2010), a condição de mestiça de Mei-Lai, loira e de olhos claros, filha de um português e de uma chinesa, que nasceu em Macau, no final da Guerra do Pacífico. A mãe da criança foi vendida pelos pais aos 6 anos de idade, para ser escrava doméstica (mui-chai) de uma tirana, que a ofertou à dona de um tancar, uma pequena embarcação de transporte de pessoas e mercadorias, na região do Porto Interior. No bairro flutuante macaense, a serva, frequentemente espancada, aprendeu o duro ofício e foi alforriada pela sua proprietária, de quem herdou o barco. Em 1944, o poder do acaso, cristalizado no pedido de Manuel, marinheiro da canhoneira Macau, para deslocamento pessoal dele, transformou a vida da jovem masculinizada, que tinha braços musculosos e mãos calejadas, mas era de natureza sensivel e delicada. A narrativa do escritor macaense, que aborda a dificil situação dos pais e de Mei-Lai, que tinha traços europeus (eurasiana), em uma sociedade taoista, colonizada por Portugal, será analisada segundo as reflexões sobre a identidade macaense, a mestiçagem e o estigma (Goffman).

Palavras-chave: Literatura macaense. Henrique de Senna Fernandes. Narrativa. Mestiçagem. Estigma.

Abstract: The aim of this study is to analyze in Henrique de Senna Fernandes's "A- Chan, a tancareira" (1950), the mestizo condition of Mei-Lai, blonde and light-eyed, the daughter of a Portuguese and a Chinese, born in Macao at the end of the Pacific War. The mother of the child, was sold by her parents at age 6 to be a tyrant's domestic slave (mui-chai), who offered it to the owner of a tancar, a small people-carrying vessel and goods in the Porto Interior region. In the floating neighborhood of Macao, the servant, often beaten, learned the hard work and was freed by her owner, who inherited the boat. In 1944, the power of chance, crystallized at the request of Manuel, a sailor from "Macau" gunboat, for his personal displacement, transformed the life of the masculinized young woman, who had muscular arms and calloused hands, but was sensitive and delicate in nature. The narrative of the Macanese writer, which address the plight of parents and Mei-Lai, who had European (Eurasian) traits, in a Taoist society. colonized by Portugal, will be analyzed according to reflections on Macanese identify, mestizaje and stigma (Goffman).

Keywords: Macanese literatura. Henrique de Senna Fernandes. Narrative. Mixed race. Stigma.

\section{(c) (1)}




\section{Introdução}

No ano de 1950, aos 27 anos, Henrique de Senna Fernandes, ${ }^{2}$ estudante macaense do curso de Direito da Universidade de Coimbra, recebeu o "Prémio Fialho de Almeida", outorgado durante os Jogos Florais da Queima das Fitas da instituição, com "A-Chan, a tancareira": uma narrativa sobre a dura labuta de uma moça chinesa que transportava pessoas e mercadorias no seu pequeno tancar (barco), no Porto Interior de Macau, e que se apaixonou por Manuel, um marinheiro português, que ela chamava de Cou-Lou, Homem Alto.

Em "A-Chan, a tancareira", o escritor evoca cenas de Macau, dividida pela colonização lusa entre a cidade chinesa e a cidade portuguesa, durante a Guerra no Pacifico, durante a qual fora invadida por refugiados da "terra-china", Cantão, Hong-Kong e Xangai. Além de ter sido ocupada por japoneses (1941-1945), e bombardeada por eles e norte-americanos (1942 e 1943), apesar da condição de neutralidade do governo metropolitano de António Salazar.

O reconhecimento literário do estudante macaense em Coimbra e o seu talento e gosto pela escrita foram consolidados em contínua colaboração em vários jornais e revistas de sua terra natal, ao longo de sua vida: A Voz de Macau, Noticias de Macau, O Clarim, Gazeta Macaense, Revista de Cultura e Mosaico, publicado pelo Círculo Cultural de Macau. Além de ter escrito sobre cinema, na década de 1970, na revista Confluência, órgão de informação da Associação para a Defesa dos Interesses de Macau (ADIM) (RANGEL, 2010, p. 90).

A publicação de suas obras ocorreu nos anos 1970 a 1990: Nam-Van: contos de Macau (1977) e Mong-Há: contos de Macau ${ }^{3}$ (1998) e os romances, Amore Dedinhos de Pé (1986) e A Trança Feiticeira (1993), ${ }^{4}$ além de Os Dores (incompleto), publicado, postumamente, em 2012, e A Noite Desceu em Dezembro, em 2015. O País das Orquideas não foi publicado.

Nam-Van e Mong-Há são títulos que aludem a espaços geográficos macaenses, segundo Celina Veiga de Oliveira em O Conto na Obra de Henrique de Senna Fernandes:

Nam-Van é a Praia Grande, a orla da suave baía
em meia-lua - agora muito desfigurada - que,
durante séculos, foi musa de pintores e de es-
critores; Mong-Há é uma vasta área da cidade
que, nos anos de infância do escritor, era uma
planura recortada de hortas e várzeas de arrozal,
com um lago de água limpida e pura e quadros
de vida rural chineses, apenas chamuscada
por humildes povoações e esparsas casas de
campo (OLIVEIRA, 2011, p. 853, grifo da autora).

Os temas literários de Senna Fernandes são variados e refletem aquela sociedade permeada por distintas etnias, culturas, religiões, idiomas e costumes, na qual eram celebradas festas natalinas e taoistas (Ano Novo Lunar), e permanecia a tradição de "comidas de pão" (europeia) e de "comidas de arroz" (macaense), do "chá-gordo" e do coulau (restaurante chinês), bem como a compreensão ambiental da quiromancia feng shui e os ritos nos templos.

Havia algumas pessoas com trajes e penteados europeus e, outras, com uma única e longa trança e cheong-sam (cabaias compridas); elas divertiam-se com vários jogos de tabuleiro (má-cheok, pai-kao etc.) e com sessões de "autochinas" (teatro chinês). Fumava-se tabaco e inalava-se ópio; perfumava-se a casa com incenso e sândalo.

\footnotetext{
2 Depois de concluir seus estudos, em Coimbra, Henrique de Senna Fernandes regressou a Macau, em 1954, depois de oito anos, e começou a atuar como advogado e como professor do Liceu Nacional Infante D. Henrique e, a partir de 1955, foi nomeado diretor da biblioteca da mesma instituição de ensino. Posteriormente, ele assumiu o cargo de bibliotecário da Biblioteca Nacional de Macau, bem como o de diretor e professor de história na Escola Comercial Pedro Nolasco, o de diretor do Centro de Informação e Turismo de Macau e o de sócio fundador da Associação Doci Papiaçam Di Macau, entre outros (ESTÁCIO, 2010, p. 17). Senna Fernandes foi eleito Académico Correspondente Português da Academia Contemporânea e da Academia de Ciências de Lisboa e recebeu dois doutorados honoris causa em Literatura do Instituto Inter-Universitário de Macau (2006) e da Universidade de Macau (2008).

3 Nam-Van tem seis contos: "A- Chan, a tancareira"; "Um encontro imprevisto"; "Chá com essência de cereja"; "Uma pesca ao largo de Macau"; "Candy" e "A desforra dum china-rico".

Mong-Há apresenta cinco narrativas: "Um conto de Natal"; "A minha primeira comunhão"; "Os bons fantasmas"; "Ódio velho não dorme" e "Yasmine".

4 Os dois romances tiveram uma adaptação cinematográfica. Amor e Dedinhos de Pé (1991), um filme luso-franco-espanhol, estreado em1992, em Macau. Adaptação e realização de Luis Filipe Rocha e Izaías Almada, baseada no romance homônimo de Senna Fernandes, com Ana Torrent como Victorina Vidal, e Joaquim de Almeida como Francisco Frontaria.A Trança Feiticeira (1993), um filme macaense. Adaptação e realização de Cai Yuan-Yuan e Cai An-an, baseada no romance homônimo de Senna Fernandes, com Ricardo Carriço, como Adozindo, e Ning Jing, como A-Leng.
} 
Os amores entre chineses, entre chineses e europeus, e entre descendentes de portugueses destacavam-se: os relacionamentos felizes, interditos, tristes e desvairados (paixão por artista de teatro e por uma mulher que escondia ser um homem); o abandono de chinesas engravidadas por portugueses e seus filhos bastardos (os "trás da porta") etc.

O comércio humano, que era proibido pelas autoridades portuguesas, mas mantinha-se, foi denunciado: a venda de crianças para adoção; o tráfico de meninas para a escravidão, para a prostituição e para o concubinato; espancamentos e outros abusos físicos e psicológicos infantis; os leilões de virgens em bordéis, entre outros, que violavam os direitos humanos.

A marginalização de pessoas leprosas e com enfermidades foi registrada; também a questão dos refugiados da "terra-china", durante a guerra do Pacífico: a miséria, a fome a prostituição infantil recorrentes foram temas das crônicas literárias de Senna Fernandes.

Grupos marginais chineses foram enfatizados: o das mulheres (as com pés chipins ou de cabras, deformados e diminutos); as casamenteiras; as aguadeiras; as tancareiras; as penteadeiras; as costureiras; as bailadeiras e cantadeiras prostitutas (pei-pá-tchais); as concubinas; as escravas (mui-chai) chinesas, as não chinesas e as forras; as serviçais domésticas, conhecidas como criações ou crioulas (órfás ou enjeitadas), as empregadas das fábricas de fósforos, foguetes e tabaco; entre outras atividades subalternas no comércio; e o dos homens (os "mestre-chinas", curandeiros e hervanários; os sai-kos (pajens e recadeiros); os condutores de cadeirinhas ou de jirinquixás; os comerciantes; os pescadores; os cules; os landins de Moçambique; os artistas etc.).

A paisagem sociocultural da Cidade do Santo Nome de Deus de Macau, nas décadas de 1910 a 1940, bem como aquela dos distintos grupos sociais e religiosos da cidade cristã e da cidade taoísta da capital e adjacências, imersa na estrutura colonial portuguesa, eternizaram-se nas narrativas de Senna Fernandes, segundo o Elogio acadêmico do Doutor Henrique Rodrigues de Senna Fernandes, de Maria Antónia N. Espadinha:

\begin{abstract}
As ruas de Macau, as velhas praias hoje desaparecidas, as fontes, os bairros chineses e cristãos saem das páginas de Henrique de Senna Fernandes e ganham cor, voltam a ganhar vida, e é a Macau antiga que retorna, é a sua história, a história dos seus filhos mais humildes, dos seus costumes e das suas tradições. Também nos contos encontramos recortes de uma realidade que, através deles, não será esquecida. Os pequenos quadros da diversidade de Macau, a galeria de personagens reais, porque decalcadas da realidade, porque vistos a uma luz de compreensão e amor sempre presentes, porque é na obra de Senna Fernandes que eles se eternizam (ESPADINHA, 2008, p. 20).
\end{abstract}

Figura 1 - Macau (Final dos anos 1940): Panorama da Praia Grande até o Farol da Fortaleza da Guia, no morro, entre pinheiros

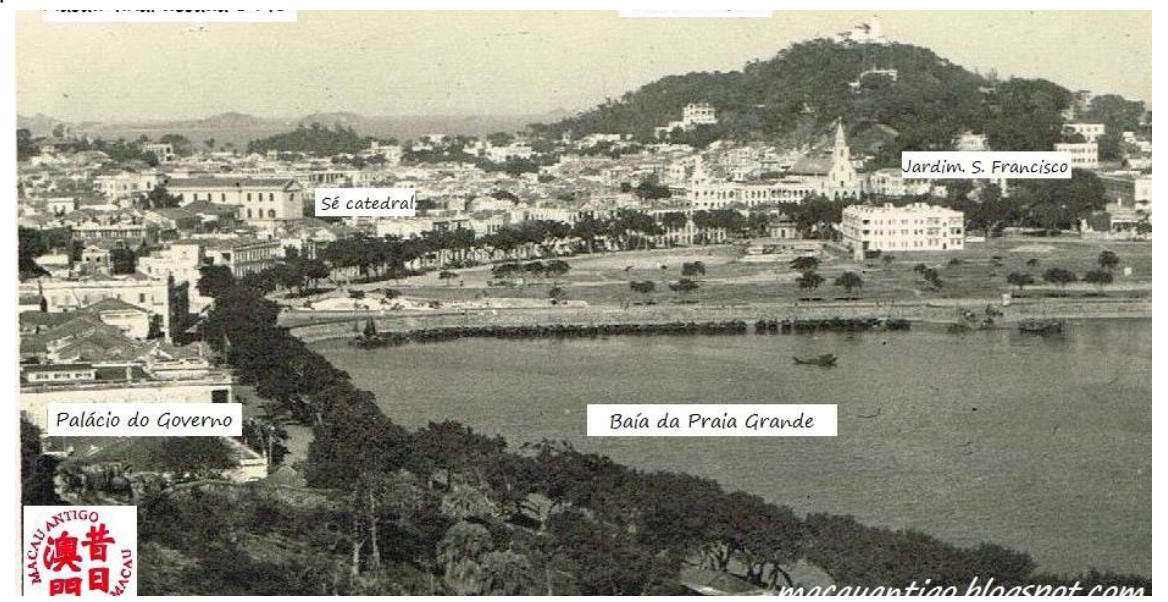

Fonte: MACAU ANTIGO, [2008]. ${ }^{5}$ 
Em suas divagações, o marinheiro Manuel, protagonista de "A-Chan, a tancareira", contemplava o panorama geográfico da cidade (o mar, os montes adjacentes, a ilha Verde, a ilha da Lapa e a baía das Cacilhas) e o arquitetônico colonial (o sacro: A Ermida de Nossa Senhora da Penha da França, com a capela homônima e a capela de Nossa Senhora do Bom Parto; e o profano: o social (o Jardim de Camões, o jardim da Montanha Russa, a praça de Tap- Seac), e o militar (a Fortaleza da Guia e a Fortaleza de D. Maria II e o seu mirante). O português, de natureza melancólica, tinha saudades das antigas viagens maritimas na África, na Índia e no Extremo Oriente e:

[...] Isolava-se, ensimesmado, preferindo a solidão dos pontos recatados. Gostava, sobretudo, de admirar os crepúsculos da Penha, de admirar o sol a esconder-se por trás da Lapa imponente. Assistia, empolgado, ao regresso lento e cansado dos juncos, atulhados de peixe saltitante. Enternecia-o o ramalhar dos pinheiros da Guia que the blandiciavam recordações. O Mirante de D. Maria, onde os seus olhos furavam o maraté o horizonte e acarinhavam as Nove Ilhas, ${ }^{6}$ sentinelas verdes que guardavam os caminhos maritimos. O jardim de Camões, as suas frondes frondosas sussurrantes. Passava tardes inteiras na curva do Bom Parto, junto à barraca do pescador, a presenciar a recolha das redes, onde pranteavam mugens e tainhas. Ou nas verduras do Campal em brincadeira com a petizada do Tap-Seac, sob o olhar vigilante das criadas. Estrada de Cacilhas, Montanha Russa, Ilha Verde. Recantos da Cidade do Santo Nome de Deus, a cujo silêncio e beleza ia rogar sossego para os seus pesares (SENNA FERNANDES, 2008, p. 5).

Nesse mesmo conto, o narrador delineia a paisagem do Porto Interior, localizado no rio das Pérolas: na parte interna, ele abriga uma população flutuante, constituída por proprietários e funcionários de embarcações e, na parte externa, a zona boêmia: "Do rio elevavam-se tênues sonidos dum povo que dormia. Marulhos de água nos cascos das lorchas e das sampanas. Pregões tristes de vendilhão de iguarias, Vago carpir de violino e flauta nativas, gorgeio de voz feminina a cantar no bairro de amor" (SENNA FERNANDES, 2008, p. 3).
Figura 2 - Brasão de Sena Fernandes

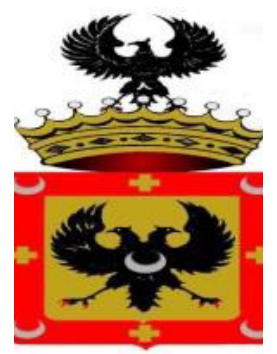

Fonte: DocPayer?

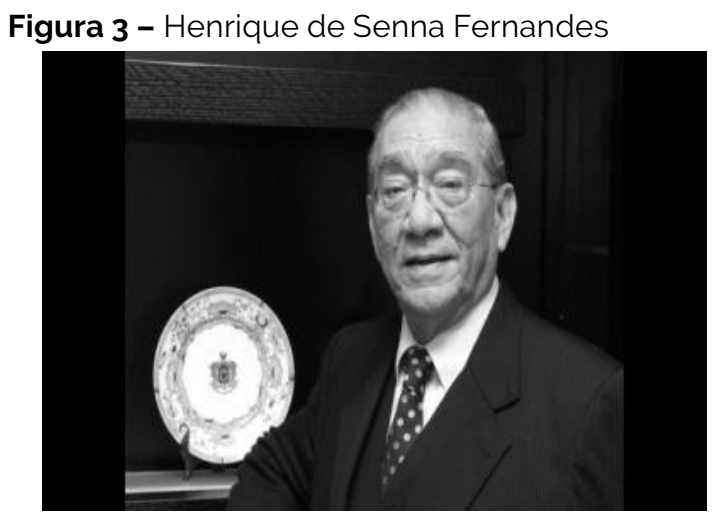

Fonte: Página do Facebook de Henrique de Senna Fernandes. $^{8}$

De ascendência chinesa e falante do cantonês (um dialeto do chinês Yue), Henrique Miguel Rodrigues de Senna Fernandes nasceu em Macau, no dia 15 de outubro de 1923, oriundo de uma das mais ilustres famílias de luso-descendentes macaenses. Era descendente de Bernardino de Senna Fernandes, grande proprietário e comerciante, que recebeu o título $1^{\circ}$ Barão de Sena de Fernandes, concedido pelo Decreto de 25 de outubro de 1888 , do rei D. Luís. Bernardino, que recebeu as armas com o Timbre - uma águia de negro andante e armada de vermelho -, era também cônsul honorário da Itália e Sião. (ESTÁCIO, 2010, p. 17). Na narrativa, "Uma pesca ao largo de Macau", o autor evocou um episódio ocorrido no rio das Pérolas com o seu avô, o conde Senna Fernandes, rico e pai de numerosos filhos.

No ano de 2007, aos 83 anos de idade, o escritor, em entrevista concedida a Isabel Castro,

\footnotetext{
6 As nove ilhas são: Verde, Lapa, D. João ou Macarira, Montanha ou Tai-Vong-Cam, Coloane e ilhéu dos Lázaros, e Taipa (Tiap’á), formada pela Taipa Grande, Taipa Pequena (Arco do Dragão, Long Wan ou Siu Tan Chai) e ilhéu Kei Kiong.

7 Disponivel em: https://docplayer.com.br/72149458-Na- peugada-de-henrique-r-de-sena-fernandes.html. Acesso em: 7 set. 2020.

8 Disponivel em: https://web.facebook.com/Henrique.SennaFernandes/?_rdc=1\&_rdr. Acesso em: 7 set. 2020. Ver também Entrevista com Henrique de Senna Fernandes. Disponivel em: https://www.youtube.com/watch?v=SITfDXKzeC8. Acesso em: 7 set. 2020.
} 
publicada com o título "Henrique de Senna Fernandes: O miúdo que escrevia romances de amor", no periódico Tai Chung Pou Domingo, na edição de 30 set. 2007, confessou que sentia "um isolamento em Macau", revelando "muita prudência à publicação dos seus escritos actuais". A origem de tal postura retraida na escrita e lançamento de novas obras deveu-se à uma experiência vivenciada, passada há dez anos, que o desmotivou:

"Uma das coisas que me quebrou o ritmo foi quando pensei em concorrer com o 'Amor e Dedinhos de Pé' a um prémio em Portugal. Numa conversa em Lisboa alguém me disse que dificilmente poderia ser considerado um escritor português, eu sei que quem o disse não teve a minima intenção de me ofender, foi com boa fé". Na altura riu-se do comentário, mas não concorreu. Para o então septuagenário que tem Portugal catalogado como "a Pátria e Macau a Mátria", ficou a certeza de poder dizer que "sim sou um escritor de Macau", numa terra pouco pródiga em matéria literária local (SENNA FERNANDES, 2007 apud CASTRO, 2007, p. 1).

Na mesma entrevista, o autor, admitiu que muitas de suas personagens eram baseadas em pessoas reais: "Fisicamente as personagens existem, ou eram misturas de várias pessoas, depois deixa-se correr a imaginação. Certos factos eram retirados da vida de Macau daqueles tempos. [...] A A-Chan é, em parte, fruto da imaginação, mas fisicamente existiu porque eu vi-a" (CASTRO, 2007, p. 1).

Escrita em Coimbra, a narrativa "A-Chan, a tancareira" (1950)9 aborda na Cidade Santa do Nome de Deus de Macau, o encontro afetivo entre A-Chan, pequenina, olhos e cabelos escuros, e taoísta, e Manuel, alto, olhos azuis e cabelos loiros, e católico. A moça conhecia algumas palavras da língua portuguesa, e o marinheiro da canhoneira Macau, era falante de cantonês e morava havia anos naquela cidade portuária.

A conexão inusitada com o "estrangeiro do diabo", desestimulada pelas colegas dela, e pelos companheiros dele, que criticavam o seu "gosto degenerado" (SENNA FERNANDES, 2008, p. 2, 10), rompeu a rotina diária de dois seres, solitários e fragilizados, imersos na engrenagem colonial ultramarina. A-Chan foi vendida pelos pais, quando tinha 6 anos de idade para ser escrava doméstica (mui-chai) de uma mulher cruel, que a renegociou com a proprietária de um tancar, que transportava pessoas e mercadorias, na região do Porto Interior. No bairro flutuante macaense, a menina, vítima de violência física e psicológica, foi alforriada e aprendeu a conduzir com destreza o barco, que foi sua herança, depois do falecimento de sua patroa. Em 1944, começou a transportar o marinheiro Manuel. Iniciaram um terno relacionamento, durante a época de bombardeamentos aéreos de Macau. Ao defender o palacete de um rico comerciante, ele foi gravemente ferido com tiros e transportado para a ilha de Coloane. Sem notícias do amado, a jovem descobriu-se gestante e, no tancar, deu à luz uma menina loira e de olhos claros. Ao retornar, o pai encantou-se com Mei-Lai e alugou uma casa para eles na Praia de Manduco, onde A-Chan começou a ser respeitada pela comunidade. No final da guerra, Manuel solicitou autorização para permanecer mais tempo em Macau, mas nada conseguiu e, ciente do futuro ruim para sua filhinha mestiça, decidiu levá-la para Portugal (Sai-long), a fim de ser educada por sua irmã. Desesperada, a mãe entregou a pequenina, que ainda engatinhava, para o pai, que do tancar passou para a lancha e o navio.

O objetivo desse estudo é analisar no conto "A-Chan, a tancareira" (1950), de Henrique de Senna Fernandes (1923-2010), a condição de mestiça de Mei-Lai, a filha de um português e de uma chinesa, nascida em Macau, no final da Guerra do Pacífico. A narrativa do escritor macaense, que aborda a difícil situação dos pais e de Mei-Lai, que tinha traços europeus, em uma sociedade 
taoísta, colonizada por Portugal, será analisada segundo as reflexões sobre a identidade macaense, a mestiçagem e o estigma (Goffman)

\section{A identidade macaense}

Em O Macau Bambu: sobre a identidade étnica macaense e a sucessão das gerações, João de Pina Cabral e Nelson Lourenço enfatizam: "a relação entre a reprodução temporal de uma identidade étnica e o ciclo vital dos seres humanos que assumem esta identidade" (CABRAL; LOURENÇO, 1993. p. 523). Os autores explicam que:

Uma das principais categorias da identidade étnica em Macau hoje é a de "macaense" em português e touz saang 1 em cantonense - categoria que tende a aplicar-se aos euro-asiáticos de raiz cultural portuguesa e católica originários do Território. Ainda que uma larga maioria da população do território seja chinesa e que a elite administrativa seja maioritariamente constituida por portugueses da República, os macaenses desempenham um papel central em Macau uma vez que, dentro destes principais grupos étnicos, eles constituem o grupo que está mais fortemente associado com a identidade histórica do território - significado, aliás, implícito na expressão cantonense tou saang jai (lit. filho da terra) (CABRAL; LOURENÇO, 1993, nota 2, p. 524).

É necessário lembrar-se que a população macaense é miscigenada. No artigo "Escravatura, concubinagem e casamento em Macau: séculos XVI-XVIII", Leonor D. de Seabra e Maria de Deus B. Manso afirmam que, desde o final do século XVI:

\begin{abstract}
Macau tornou-se a base das operações comerciais, e muitos dos comerciantes já partilhavam a vida com mulheres estrangeiras ou luso-asiáticas (japonesas, malaias, indianas, entre outras), sendo muitas delas escravas. Algumas negras africanas e numerosas escravas timorenses foram importadas mais tarde, contribuindo para a mistura racial (SEABRA; MANSO, 204, p. 107).
\end{abstract}

Os portugueses casaram-se também com goesas, siamesas, indo-chinesas e tancares.

\subsection{A situação dos tancares}

Figura 4 - Tancareiras aguardam os passageiros, em fila, no Porto Interior de Macau

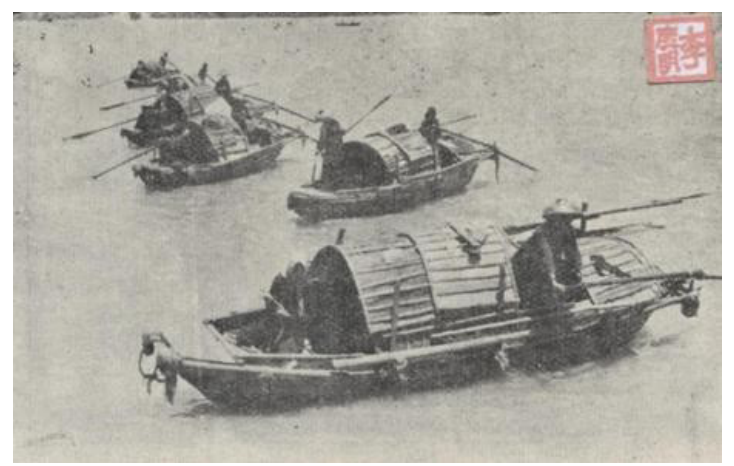

Fonte: Blog nenotavaiconta. ${ }^{10}$

O termo tancá, segundo Graciete N. Batalha, no Glossário do Dialecto Macaense tem duplo significado (embarcação e família):

[...] O tancá é barco de pesca ou de transporte a pequenas distâncias e serve também de habitação. É parcialmente coberto com um toldo em forma de túnel e dai the veio o nome. [...]

Étimo - ch. tán ká 蛋家, literalmente 'ovo-casa', isto é, casa em forma de ovo, talvez porque o pequeno barco, com seu toldo, faz lembrar um ovo boiando. A palavra ká signfica também 'familia', donde tancá aplicado à gente do mar [...] (BATALHA, 1977, p. 277-278).

Os tancares eram um subgrupo étnico do grande universo chinês, que era "caracterizado por ser um povo marítimo com baixo prestígio social. Aos tancares era impedido o acesso aos exames conducentes aos graus acadêmicos necessários para integrar a burocracia da Dinastia Qing (16441911)" (CABRAL; LOURENÇO, 1993, nota 5, p. 526).

No ano de 1837, o procurador português de Macau, em uma carta ao Mandarim de Cantão, evocou a legislação imperial Qing sobre os povos tancares (mulheres) que: 
[...] os impede de viver em terra, pois teme as arruaças que poderiam resultar as actividades de prostituição a que estes se entregam, seduzindo "soldados", "moços" e "negros". Prevendo a possibilidade de distúrbios, o Procurador passa assim ao Mandarim a responsabilidade "de qualquer desastroso acontecimento de que ali aconteça (CABRAL; LOURENÇO, 1993, nota 2, p. 526).

Apesar da marginalidade social dos tancares, os portugueses uniram-se às mulheres deste grupo, conhecidas, como mulheres do tanque ou pessoas de pesca, pois as chinesas han não aceitavam o casamento com ocidentais.

Muitos trabalhos penosos são desempenhados por homens e mulheres, na China. A condução dos tancares, que exige habilidade técnica e extrema força muscular, ainda está a cargo das mulheres em Macau e nas ilhas adjacentes Taipa e Coloane.

A protagonista de Senna Fernandes, a mui-chai doméstica A-Chan, obediente e trabalhadora incansável, foi comprada pela experiente tancareira:

A Velha conduziu-a para o extremo do delta, para a cidade branca dos portugueses e botou-a a trabalhar naquele pedaço de rio que era o Porto Interior. No começo, os labores foram dificeis, extenuante para a sua minguada compleição de tancareira incipiente. Mas a saúde triunfou e depressa se integrou naquela existência aventurosa (SENNA FERNANDES, 2008, p. 1).

Nascida de pais agricultores, A-Chan adquiriu a identidade de tancareira e a de macaense que amava Manuel: "Sensibilizava-o a maneira como lhe sorria, como the oferecia a tigela de chá ou como the passava os dedos calosos e ásperos pelos seus cabelos louros de europeu, num requinte de familiaridade" (SENNA FERNANDES, 2008, p. 6). Desse terno relacionamento foi concebida Mei- Lai, que, no contexto colonial português, tinha a condição de mestiça eurasiana, cuja aparência the reservava um futuro de estigmatizada social.

\section{Estigma e mestiçagem}

Na obra Estigma: Notas sobre a manipulação da identidade deteriorada, Erving Goffman elenca dois momentos da criação e consolidação do conceito do estigma, em relação a "sinais corporais", na era grega e cristãa ${ }^{11} \mathrm{O}$ termo, criado pelos gregos, indicava sinais corpóreos (cortes e queimaduras) como forma de exteriorização de condição de escravo, criminoso ou traidor. Posteriormente, certos tipos de erupção sobre a pele sinalizavam graça divina, e na acepção médica, e eram consideradas marcas de distúrbio físico. De alterações visuais no corpo, provocadas por herança genética ou por enfermidade, acidente ou tortura, a palavra estigma sofreu mudanças: [...] é amplamente usado de maneira um tanto
semelhante ao sentido literal original, porém
é mais aplicado à própria desgraça do que à
sua evidência corporal. Além disso, houve al-
terações nos tipos de desgraças que causam
preocupação. Os estudiosos, entretanto, não
fizeram muito esforço para descrever as pre-
condições estruturais do estigma, ou mesmo
para fornecer uma definição do próprio con-
ceito (GOFFMAN, 1988, p. 5).

Hoje em dia, segundo Goffman, o conceito estigma refere-se à desgraça exteriorizada pela evidência no corpo. Ao ampliar a questão da infelicidade, provocada por alguma diferença física, em comparação ao corpo de outra pessoa, é possivel expandir a compreensão ao mestiço que, em uma sociedade colonial, ficaria às margens, na condição de inadequado.

Em relação à composição da personagem, a menina mestiça Mei-Lai, Senna Fernandes admitiu que conheceu uma moça que, por ser eurasiana, tinha sucesso na vida noturna: "...] a Maria Marinheiro de Macau, filha de um marinheiro que abandonou a descendente, 'bailarina de um cabaret que existiu no Porto Interior, chamado O Gato Preto, uma rapariga linda, uma chinesa com traços europeus" (SENNA FERNANDES, 2007 apud CASTRO, 2007, p. 1).

A preocupação de Manuel era que sua filha, caso permanecesse com a mãe, teria a vida dissoluta na prostituição e, por isso, a levou para sua pátria.

\footnotetext{
11 Os gregos que tinham bastante conhecimento de recursos visuais, criaram o termo estigma para se referirem a sinais corporais com os quais se procurava evidenciar alguma coisa de extraordinário ou mau sobre o status moral de quem os apresentava. Os sinais eram feitos com corte ou fogo e avisavam que o portador era um escravo, um criminoso ou traidor uma pessoa marcada, ritualmente poluída, que devia ser evitada; especialmente em lugares públicos. Mais tarde, na Era Cristã, dois niveis de metáfora foram acrescentados ao termo: o primeiro deles referia- se a sinais corporais de graça divina que tomavam a forma de flores em erupção sobre a pele; o segundo, uma alusão médica a essa alusão religiosa referia-se a sinais corporais de distúrbio físico (GOFFMAN, 1988, p. 5).
} 


\subsection{Macau: história e tradição}

Figura 5 - Península de Macau e as nove ithas e ilhéus (anos 1930). Ligada ao continente (Cantão) pelo istmo, conhecido como Porta do Cerco

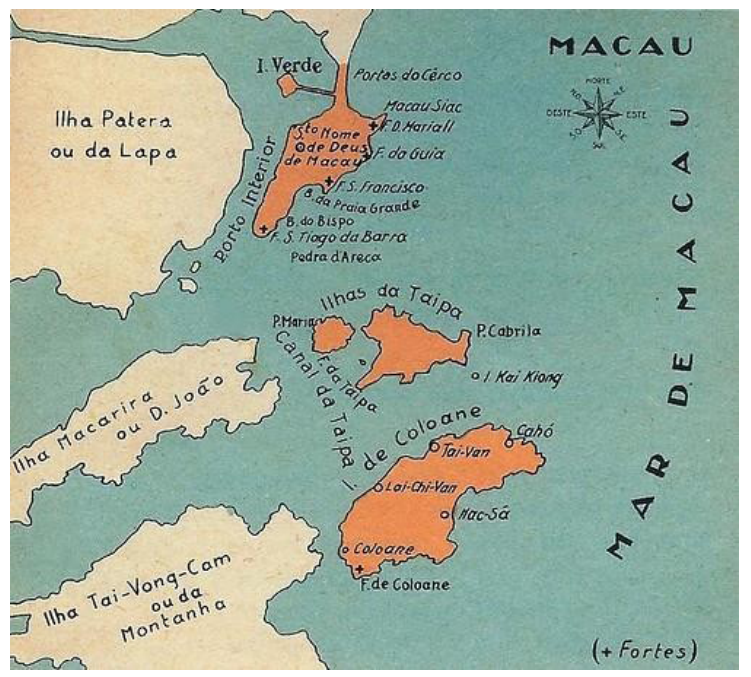

Fonte: Blog da Rua Nove. ${ }^{12}$

A península de Macau ${ }^{13}$ localiza-se no delta de dois rios - o Chu-Kiang (rio das Pérolas ou rio do Leste) e Si- Kiong (rio do Oeste) - e cerca de 80 milhas do porto de Cantão (Guangzhou, hoje), capital da província de Kwang-Tung, e de 60 km de Hong- Kong.

Depois da ocupação de Goa (1505) e de Málaca (1511), na época de D. Manuel I (1469-1521) e do imperado chinês, Zhengde (1491-1521), da dinastia Ming, o português Jorge Álvares, em 1513, levantou um padrão luso na ilha de Tamão (atual ilha de Lantau), localizada na desembocadura no rio das Pérolas. Em 1516, Rafael Perestello atracou no porto chinês, Kungchow, denominado de Cantão, e obteve licença para comerciar. Foram construidas fortalezas, fato que desgostou o imperador e inter- rompeu os planos da expedição de Tomé Pires de ir até a capital, a fim de manter relações diplomáticas. Eles foram expulsos, cinco anos mais tarde (YANG, 1976, p. 32, 38), conforme Alexander Chung Yuan Yang, no artigo "O comércio de Cantão" (1720-1796).

Em 1540, os portugueses expandiram novas feitorias ao sul da península de Macau, às ilhas de Sanchuang e Lampacau e até o Japão. Por volta de 1555. Macau tornou-se um importante centro de comércio entre a China, Japão e Goa.

De 1555 a 1557, os portugueses solicitaram ao vice-rei e aos mandarins de Cantão, a permissão para fixação nas ilhas de Liampó e, depois, na península, na qual havia um templo dedicado à deusa A- Má, divindade dos marinheiros. Nesse local foi fundada a vila de Porto do Nome de Deus, mudado para Cidade do Nome de Deus, em 1586.

Durante a dinastia Qing (1644-1912), a península de Macau e ilhas tinham uma dupla soberania: a população chinesa estava subordinada às autoridades de Cantão, enquanto a população portuguesa e descendente era administrada pelo governo colonial luso. ${ }^{14}$

Em 13 de agosto de 1862, na época da regência de Tseu-Hi (1861-1908), a China e Portugal assinaram, mas não ratificaram o Tratado de Comércio de Tianjin. Somente no dia 26 de março de 1887. foi assinado o Tratado de Amizade e de Comércio Sino-Português, ratificado em $1^{\circ}$ de dezembro do mesmo ano, o qual conforme Ma Siyuan, na dissertação Um olhar português sobre a China: As relações luso-chinesas nas obras de alguns autores portugueses: "vinha dar tranquilidade às autoridades político-administrativas. Acabava com um periodo de instabilidade e de incertezas,

12 Disponivel em: https://blogdaruanove.blogs.sapo.pt/254969.html. Acesso em 7 set. 2020.

13 O nome Macau tem origem na denominação da Baía de A- Má, por causa do templo homônimo (A- Ma Gao, em cantonês), A-Ma Gao tornou-se Amacao, Macao e Macau (HISTÓRIA..., [2018]).

No ano de 1849, Macau foi declarada território português, com reconhecimento chinês e, em 1951, território ultramarino de Portugal. Em 1979, ficou assentado que Macau como território chinês, estaria sob administração portuguesa. No ano de 1987, foi assinada uma Declaração Conjunta entre a China e Portugal com a determinação de que Macau passaria à soberania chinesa, em 20 de dezembro de 1999. com o status de Região Administrativa Especial da República Popular da China.

14 A situação comercial de Macau mudou com as Guerras do Ópio (1839-1842) e com a fundação de Hong-Kong pelos ingleses, em 1840. Como reação, o governo de D. Maria II (1819-1853), tomou drásticas medidas para Macau, a partir do ano de 1845, a serem implementadas por Ferreira do Amaral (1803-1849), nomeado o primeiro governador colonial. No mês de outubro de 1846, ele anunciou um imposto sobre os barcos de transportes, os fatiões, que provocou o assalto de barqueiros no Forte de São Paulo. Além disso, acabou com o pagamento do foro do chão (1846) (CABRAL; LOURENÇO, 1993, nota 2, p. 526).

Ferreira do Amaral determinou a diminuição do poder do Leal Senado de Macau; o estabelecimento do seu poder total como governador geral do território; a submissão à administração direta de Lisboa, ao invés de Goa; a declaração de Macau como porto franco; a unificação das alfândegas portuguesa e chinesa, sob administração lusa. Suas decisões para cumprimento das determinações de Lisboa resultaram em seu assassinato, no ano de 1849, segundo Mário César Lugarinho, no artigo "Violência e interpretação, leituras da História de Macau" (LUGARINHO, 2018, p. 38). 
ao definir uma plataforma de permanência e convivência minima" (SIYUAN, 2015, p. 43).

\section{A canhoneira Macau e a Guerra do Pacifico (1939-1945)}

Figura 6 - Canhoeira Macau

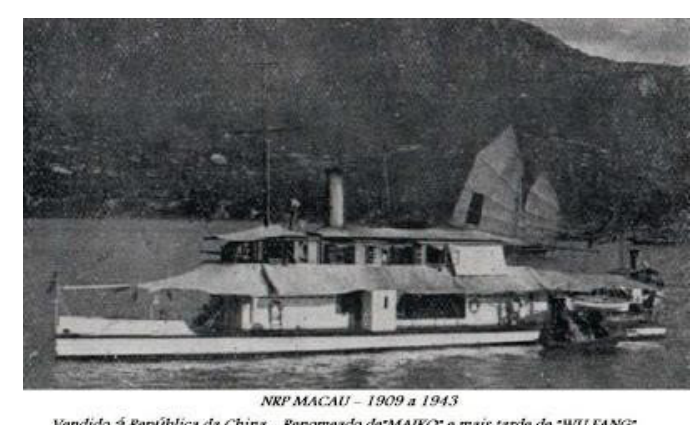

Fonte: Macau Antigo. ${ }^{15}$

Durante a Guerra do Pacífico, apesar da neutralidade de Portugal, Macau e o Timor Português foram invadidos pelos japoneses. 0 Japão ${ }^{16}$ estabeleceu um consulado em Macau, que tinha funções diplomáticas e de espionagem, sob administração de Fukui Yasumitsu, que foi elevado à condição de conselheiro especial do governador de Macau, Gabriel Mauricio Teixeira (RANGEL, 2020, p. 1). O porto de hidroaviões macaenses foi bombardeado pelos nipônicos, sob a alegação de erro acidental; eles ocuparam as ilhas de Lapa, Dom João e Montanha. Nos anos 1942 e 1943. ocorreram bombardeamentos nipônicos nas montanhas da ilha da Lapa e na ilha de Chun San.

A península de Macau, depois da ocupação de Hong Kong (8 de dezembro de 1941), foi invadida por cerca de 500.000 refugiados, também provenientes de Cantão e Xangai. Tal fato agravava a situação de fome, pois os japoneses somente permitiam a entrada de arroz e outros gêneros. Em troca de alimentos, o governo local teve que entregar a eles canhões, equipamentos de co- municação e navios. A canhoneira Macau (Maiko), que tinha sido fabricada na Inglaterra pela firma Yarrow, e desempenhou várias funções no mar da China, desde 1909, foi confiscada/vendida, no dia 12 de março de 1943, em troca de 3.000 sacos de arroz, de 60 kg. cada, no total de 1 milhão de patacas. Posteriormente, a embarcação caiu nas mãos do governo chinês de Cantão, e renomeada como Wu Feng (LANCHA- CANHONEIRA, 2013, p. 1). O seu rastro dele perdeu-se na história.

Figura 7 - Distribuição de comida em Macau, durante a guerra

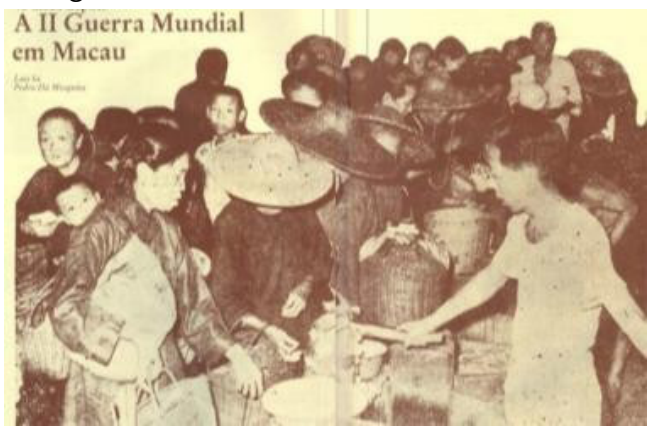

Fonte: Site Cronicas Macaenses. ${ }^{17}$

O protagonista de "A-Chan, a tancareira", o marinheiro português trabalhava na canhoneira Macau que patrulhava a península e as ilhas:

Manuel devassara mundos, estivera nos cruzeiros de África, familiarizava-se com os trópicos e calmarias, sequioso de aventura e da paixão do mar. Abordara a Macau, transferido para a marinha privativa da provincia e, durante anos se deixara seduzir pelos exotismos e sortilégios do burgo macaense. Já dava por finda a comissão, quando a guerra estalou com todo o seu cortejo de horrores (SENNA FERNANDES, 2008, p. 4).

Na época em que Macau estava ocupada por japoneses, ${ }^{18}$ a península começou a ser invadida por refugiados da "terra-china", sobrecarregando a situação de comercialização e distribuição de alimentos. Desesperada, A-Chan:

15 Disponivel em: http://macauantigo.blogspot.com/2009/04/nrp- macau-lancha-canhoneira-1909-1943.html. Acesso em: 7 set. 2020 16 A bandeira do Império do Sol Nascente foi hasteada no Palácio da Praia Grande, no dia 25 de dezembro de 1941, permanecendo até o $1^{\circ}$ de agosto de 1945. O Quartel-General foi instalado em uma faustosa residência, situada na esquina da Avenida Horta e Costa com a Rua Almirante Costa Cabral. Os japoneses tentaram montar uma barricada na avenida mencionada, mas os macaenses não permitiram, apontando peças da Fortaleza de Mong-Há e da Fortaleza da Guia (MACAU..., [2014]).

17 Disponivel em: https://cronicasmacaenses.com/2014/07/24/a-2a-guerra-mundial-em-macau-tempos-dificeis/. Acesso em: 7 set. 2020. 18 "A guerra prosseguia infindável, mas à medida que os meses rolavam, o declínio era evidente. A Macau chegavam interruptamente os párias e os deserdados da sorte que vinham pedir hospitalidade e segurança. A indigência dos refugiados de todos os lugares da China sofredora contrastava com a opulência dos novos ricos e dos japoneses que traficavam impunes à sombra duma bandeira neutral" (SENNA FERNANDES, 2008, p. 6). 
Ficou transida quando a guerra varreu a cidade, mas logo reagiu, porque era preciso trabalhar, se quisesse sobreviver. Nunca o ganha-pão the foi tão espinhoso, a fome tão negra. Com os japoneses insignificantes em redor, o negócio diminuiu, dias havendo que nem um cobre auferiam. Endureceu-se-lhe o coração, tornando-se-lhe indiferente o drama dos pobres que formigavam na cidade, outrora risonha feliz. Não a impressionava a tela fúnebre dos miseros que morriam à beira da marginal, trágicos inocentes duma sangreira que não podia compreender. A mancheia de arroz que tragava, custava-lhe tantos sofrimentos, que não podia reparti-la com quem quer que fosse (SENNA FERNANDES, 2008, p. 2).

O sofrimento, causado pela ocupação militar, racionamento e falta de víveres, foi intensificada com o início dos barulhentos e destrutivos ataques aéreos de comando norte-americano. ${ }^{19} \mathrm{~A}$-Chan e Manuel sofriam, abrigados no frágil tancar:

A-Chan também se arrepiava de pavor, mas incidia o medo na sua frágil embarcação, três tábuas a flutuar nas águas lodosas, que eram o seu ganha-pão. Sim, havia quem sofresse. 0 rio e a guerra não lhe regateavam trágicos painéis. Mas, acima das lágrimas e dos clamores dos outros estava o seu tancar, o seu sustento.

Então, abraçavam-se um ao outro desesperadamente, ele aflito pela morte que pairava no ar, ela, pela integridade do seu tancar, como se naquele desvairado amplexo estivessem a salvação e a tranquilidade num mundo em delírio (SENNA FERNANDES, 2008, p. 6).

\subsection{O estigma da mestiça Mei-Lai em "A-Chan, a tancareira" (1950)}

Na parte final de "A-Chan, a tancareira", o autor Senna Fernandes indicou: "Escrito em Coimbra, em Fevereiro de 1950, com saudades de Macau", esclarecendo que era um conto elaborado na diáspora, depois de cerca de cinco anos de vida estudantil, em uma época na qual sentia nostalgia de sua pátria.

Tal narrativa, seguida de outras de Henrique de Senna Fernandes, foram escritas em lingua portuguesa, embora o escritor fosse falante nativo de cantonês, um dialeto do chinês Yue. Em entrevista, ele recordou-se da dificuldade das crianças macaenses, que falavam chinês, em aprenderem o português. O menino Henrique também sofria para entender e memorizar a conjugação dos verbos, imperfeitos, perfeitos e mais-que-perfeitos: "Aprendi os verbos à força, na terceira classe" (CASTRO, 2007, p. 1).

Relata sobre a importância do encontro com um professor da escola primária, no quinto ano, em um curso opcional e preparatório para o ingresso no liceu: "Foi decisivo para a minha vida nas letras. Era um profundo conhecedor da língua portuguesa, um homem esquisito, que tinha estudado para ser jesuita, todo ele era jesuita" (SENNA FERNANDES 2007 apud CASTRO, 2007, p. 1). O mestre o motivou a escrever redações:

\begin{abstract}
le tinha um livro chamado Leituras Morais, em que se exaltavam as virtudes e se carregava nos defeitos. Pegava no livro e contava uma história, lendo. Tinhamos que reproduzir a história à nossa maneira. "A redacção que mudou a forma de olhar as palavras era sobre a inveja. "Escrevi e entreguei. Eu era um dos melhores a português, lia muito desde pequenino, o meu pai incutiu-nos o gosto pela leitura" (SENNA FERNANDES 2007 apud CASTRO, 2007, p. 1).
\end{abstract}

Senna Fernandes narrou que recebeu a redação corrigida com muitos traços vermelhos, com alguns verbos "ainda por apurar". Ficou desiludido, mas o professor o elogiou, dizendo que o jovem "tinha ideias" e que devia continuar. A "palavra mágica" o deixou "radiante": "Fui para casa, contei aos meus pais, mostrei, fiquei muito contente". O professor "disse que era preciso ler muito e comecei a ler ainda mais do que lia". Aos dezessete anos, ele começou a escrever histórias de amor (SENNA FERNANDES, 2007 apud CASTRO, 2007, p. 1).

Sua abastada familia ficou sem seus bens com a queda da Bolsa de Hong Kong, por causa da invasão dos japoneses, em 1941, segundo o escritor: "O meu pai perdeu a fortuna toda que tinha, ficámos praticamente na miséria. Mas uma coisa foi legada pelos nossos antepassados: um imenso orgulho, que vem da educação que recebi, o orgulho de esconder a miséria e o sofrimento" (SENNA FERNANDES apud CASTRO, 2007, p. 1). Na época, ele fugia para os livros e escrevia histórias: "Tinha como leitoras as minhas irmãs" (SENNA FERNANDES, 2007 apud CASTRO, 2007, p. 1).

19 "Nas noites claras e luarentas, sobrevoavam a Cidade do Santo Nome de Deus aviões americanos, que iam espalhar destruição nos pontos estratégicos do interior. Roncos sinistros que angustiavam os indefesos lares macaenses e traziam à boca preces de corações alanceados. Compunha-se o peito do marujo ao escutar aqueles sons cavos. A morte rondava perto na sua fereza de colher mais vitimas. Bastava um daqueles para reduzir a cidade a um montão de escombros. E ele não queria perecer, agora que o fim não podia estar longe" (SENNA FERNANDES, 2008, p. 6). 
A obra literária dele abrange facetas da cultura europeia e da macaense. Mônica Simas, no artigo "Identidade e memória no espaço literário de lingua portuguesa em Macau", enfatiza: "Como uma espécie de guardião cultural, o macaense Henrique de Senna Fernandes oferece um rastro literário cheio de cumplicidades e de demarcações para a preservação e identificação da cultura macaense" (SIMAS, 2004, p. 160).

O conto "A-Chan, a tancareira", cuja ação desenvolve-se nos anos 1943 a 1945, está dividido em quatro partes: venda da menina para a rica senhora e revenda para a tancareira; alforria da moça, morte da patroa e recebimento da embarcação como herança; eclosão da Guerra do Pacífico e ocupação japonesa de Macau; surgimento de Manuel e envolvimento afetivo (parte 1); relações íntimas entre o casal; perfil do marinheiro: vida promíscua no Oriente e reconciliação com sua irmã (parte 2); intensificação da guerra: escassez de alimentos, chegada de refugiados e bombardeamentos; descoberta da gravidez de A-Chan (parte 3); ferimento de Manuel e tratamento na ilha de Coloane, sem o conhecimento da jovem; nascimento de Mei- Lai, em uma tarde chuvosa de inverno; retorno do marinheiro e mudança da família para uma casa na Praia do Manduco; final da guerra e regresso do pai e filhinha para Portugal (parte 4).

A paisagem cultural chinesa - a literatura e oral e a religião taoísta - é evocada pelo narrador. Depois do trabalho árduo, A-Chan e outras sentavam-se ao redor da dona do tancar para ouvi-la contar lendas e contos, que revelavam valores e crenças daquela sociedade chinesa, bem como medos e temores (representações do inconsciente). Tratava-se de uma prática de transmissão oral de conhecimentos, com sabedoria de vida e com finalidade educativa:

Nas noites serenas, costumava acocorar-se na rua marginal para escutar as narrativas das companheiras em que entravam donzelas, guerreiros, dragões, lendas do rio e do mar, intrigas de femeaço e confidências de amor. A Velha, sobretudo, tinha histórias encantadoras. A sua voz rouca timbrava doçuras, quando evocava a meninice longinqua, o tempo em que a vida do rio era mais fácil, quando as festas do Ano Novo e do Oitavo Mês se faziam com um punhado de sapecas [...] (SENNA FERNANDES, 2008, p. 2).

As entusiasmadas ouvintes admiravam: "Quanta coisa sabia a Velha! Desde as mezinhas para tirar o vento sujo até os pós e exorcismos para afugentar o demônio (SENNA FERNANDES, 2008, p. 2, grifo do autor).

Outros tipos de práticas religiosas são mencionados na narrativa: no enterro da Velha e depois do desaparecimento de Manuel. A anciã faleceu em um terrivel acidente maritimo:

Vieram os bonzas para os ritos, prantearam as
amigas e as carpideiras e, por alguns dias, no
pequeno mundo das tancareiras, lastimou-se
aquela morte estúpida. Depois tudo voltou ao cur-
so normal da vida. Ea velha lá ficou descansando,
no cima dum outeiro da ilha de Lapa, no meio da
sua tribo (SENNA FERNANDES, 2008, p. 2).

Em uma noite de bombardeios aéreos, A. Chan descobriu-se gestante e ficou preocupada com: "infantil receio de que ele se zangasse por não ter sabido evitar a maternidade" (SENNA FERNANDES, 2008, p. 7), mas Manuel, sem saber da novidade, não retornou mais:

\begin{abstract}
[...] O Cou-Lou sumira-se, inexplicavelmente, Invadiu a sua alma negro desânimo. Implorou aos deuses, bateu a cabeça no pagode, acendeu os pivetes, consultou a bruxa. Tênues momentos de revolta que mal afloraram à expressão do seu rosto esmaecido. Estava-lhe, porém, nas veias o fatalismo da raça e, com ele, a sujeição milenária da mulher chinesa aos caprichos do seu homem e senhor. Se o CouLou não vinha era porque outra o enfeitiçara. Não havia que lutar, perante os desígnios dos deuses [...] (SENNA FERNANDES, 2008, p. 7).
\end{abstract}

Figura 8 - Tancareira

\section{Fonte: ICM. ${ }^{20}$}

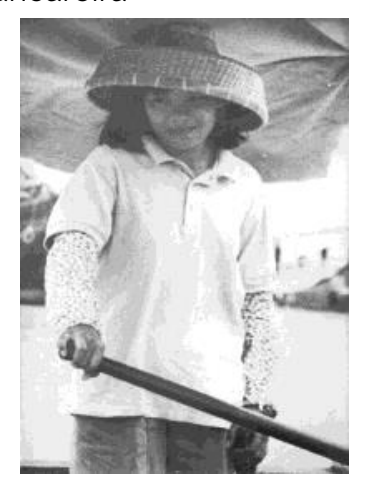

20 Disponivel em: http://www.icm.gov.mo/rc/viewer/30002/1378. Acesso em: 7 set. 2020 
A narrativa inicia-se com a informação sobre a venda infantil de meninas: um estatuto cultural que não foi impedido pela administração portuguesa. Na condição de escrava, de mui- chai, elas eram levadas de aldeias taoístas, com plantação de arroz e criação de búfalos:

Chan não era aborígene do Porto Interior. Lembrava-se confusamente da infância, a aldeia cinzenta, perdida algures no delta. Poucas reminiscências perduravam na sua memória. Búfalos ruminando nas várzeas amarelas, homens, talvez parentes, debruçados no amanho duma terra ingrata. Um pagode, alcandorado na lomba dum certo, calvos bonzos em lúgubres pantominas (SENNA FERNANDES, 2008, p. 1).

A pequena A-Chan fora: "Traficada pelos pais num terrivel ano de seca, quando mal desabrochavam os seis anos, correra de mão em mão até desembocar no rio pela mão da Velha que a comprara a uma opulenta matrona de Seak-ki. Fora um negócio vantajoso para a idosa tancareira [...]. Mas para A-Chan aquela transação foi como uma dádiva dos deuses. [...]. A dona surrava a criança: "No íntimo, porém, o tratamento parecia-lhe melhor do que na casa aristocrática, pois a Velha era menos cruel e a vida mais pletórica de novidade" (SENNA FERNANDES, 2008, p. 1). Recebida como estrangeira, a menina: "Ganhou amizades, porque não era mulher para cuvilhices e, quando podia, auxiliava as companhias necessitadas. Falava e sorria pouco. A velha apreciava-a, porque era obediente e nunca se lamuriava da sorte" (SENNA FERNANDES, 2008, p. 2).

A tancareira A-Chan era "feia, rosto macerado e trigueiro, uma resignação estampada de quem conhecia o ferrete do sofrimento. Olhos obliquos, dois traços miúdos, um nariz chato, grosseiro. Horrenda, não, simplesmente feia. Mas que terna expressão de escrava submissa" (SENNA FERNANDES, 2008, p. 5). Ela tinha medo de encarar os "estrangeiros do diabo", os "soi kuan" e, por isso, mal pisava a terra. Certo dia, somente por causa da intervenção de sua amiga A-Lin, A-Chan aceitou transportar um marinheiro, alto e loiro. Os préstimos dela prosseguiram, pois: "ele não era só liberal nas gorgetas, como também se the dirigia com delicadeza, sem os impropérios de quem paga" (SENNA FERNANDES, 2008, p. 2-3). Em uma terrivel noite, imersa em infernais barulhos de aviões inimigos, a moça teve uma revelação emocionante:

\begin{abstract}
[...] ela descobriu a insofismável nova. la ter uma criança, um filho desse homem louro, de olhos azuis, que tão suavemente a tratava. Qualquer coisa de inédito, de estupendo nasceu nela, um sentimento indefinido e ao mesmo tempo embriagador. Mas calou-se, aguilhoada por súbito pudor e infantil receio de que ele se zangasse por não ter sabido evitar a maternidade (SENNA FERNANDES, 2008, p. 7).
\end{abstract}

A notícia transformadora de sua vida não foi comunicada a Manuel, que ferido, tinha sido transportado para tratamento na ilha de Coloane, sem ter tido tempo de avisá-la. Durante a gestação solitária, a moça trabalhou infatigavelmente; após o transporte até a ilha da Lapa sentiu as dores e deu à luz em uma noite chuvosa, enquanto A-Lin manobrava o tancar.

Figura 9 - Tancareira com nenê nas costas

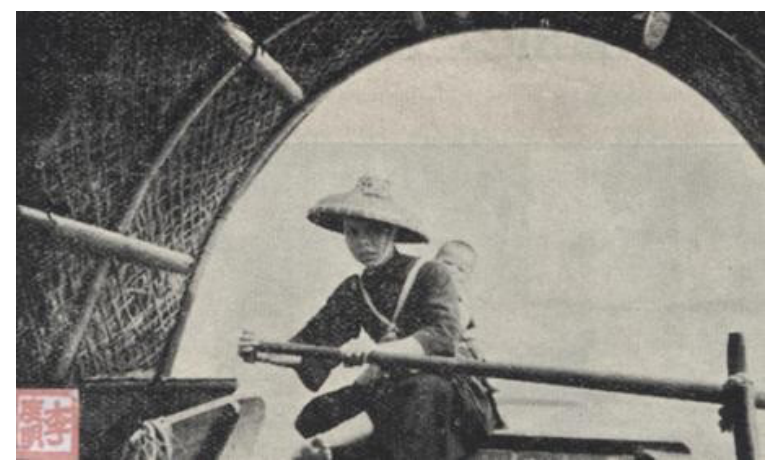

Fonte: NENOTAVAICONTA, [2014]. ${ }^{21}$

Recuperado, Manuel voltou à Macau: "Havia maior certeza de paz, quando regressou à Cidade de Santo Nome de Deus. A desintegração da Alemanha não merecia dúvidas e os aviões americanos eram mais numerosos sobre os telhados da terra macaense". Somente buscou A-Chan: "quando as aeronaves bombardearam o solo neutral e semearam morte no Porto Interior, se lembrou dela. E, diante daquela criaturinha frágile loira: "Acordou nele a paternidade, um amor pro- 
fundo pela inocente" (SENNA FERNANDES, 2008, p. 8). Mudou-se com a nenê e a mãe para a Praia de Manduco: "E como eram felizes! A tancareira soltava francas gargalhadas, sem rebuço, quando brincava com ela. E Manuel transmudava-se num gaiato, que passava horas sem fim a distraí-la". SENNA FERNANDES, 2008, p. 8). A mãe tornara-se "uma senhora que governava a sua casa, com o devido respeito da vizinhança. Orgulhava-se de Mei-Lai, como se tivesse dado à luz um rapaz [...] (SENNA FERNANDES, 2008, p. 10).

O final da guerra chegara, com a rendição da Alemanha e o esfacelamento do Japão, e Manuel tinha que regressar a Portugal: "Sabia que não podia fuçar para sempre ao pé da tancareira, porque o seu destino era o mar" (SENNA FERNANDES, 2008, p. 9). A paternidade de uma mestiça o angustiava, pois havia duas alternativas: a menina ficava com a mãe ou com ele que ponderava: "Que futuro lhe reservaria a tancareira? Cresceria no ambiente soturno do porto, acompanharia a mãe nos espinhos do ofício, maltratada pelo mundo e pela fome que é o estigma de todas as camadas paupérrimas da China". Manuel não desejava para a pequena uma vida mergulhada no estigma da pobreza, tampouco no estigma da mestiçagem. O temeroso pai sabia que as feições de Mei-Lai não eram totalmente orientais, fato que: "denunciava uma pecaminosa ligação com o europeu. Nunca vira mestiças a trabalhar no rio. Para outros caminhos as levara o destino. Para os bordéis, para as hospedarias das vielas do amor. Em toda a parte, onde nasciam rebentos clandestinos de europeus, a prostituição lucrava" (SENNA FERNANDES, 2008, p. 10). Por causa do estigma social latente, Manuel não poderia abandonar a criança e pensou "na irmã redimida, que distante acenava por ele. Decerto albergaria a sobrinha educá-la-ia com desvelo. Mas era doloroso arrebatá-la da mãe. E neste dilema se debatia a sua alma inquieta" (SENNA FERNANDES, 2008, p. 10). Decidido a levar consigo Mei-Lai, ele:

[...] trouxe consigo um intérprete que fluente nas duas linguas, poderia explicar melhor a A-Chan. Recebeu-os retraida. O intérprete, adivinhando o melindre da situação, exprimiu-se arrastadamente.
Quando ficaram a sós, fixou-o de frente. Tinha as faces terrosas, uma expressão de infinito desespero. O marinheiro, agarrado a Mei-Lai que traquinava, não suportou aquele olhar $e$ tartamudeou esculpas que não soube comple$\operatorname{tar}$ (SENNA FERNANDES, 2008, p. 11).

Abalada, a mãe consentiu, pois sabia que o futuro da menininha seria: "O rio, o eterno e inalterável rio a exigir-lhe as forças até o alento final. O tancar, os remos, o vaivém na superfície barrenta do porto. Dias incertos, privações. A velhice insegura, a perene escravatura do ofício. Sim, ele tinha razão" (SENNA FERNANDES, 2008, p. 12). Na fria noite despedida, ela cozinhou um delicioso jantar e apresentou-se com: "a melhor cabaia presente singelo do marinheiro sentimental. $\mathrm{E}$ na trança morena brilhava o pente cravejado de pedras falsas, lembrança cúmplice duma noite de amor" e, depois, o pai deu o sinal de partida: Ela assentiu resignada, aconchegando mais a si
o ente querido de quem ia se separar. Manuel
pegou nos remos e guiou o tancar para o porto,
para o cais de embarque, onde resfolegava a
lancha dos passageiros.

Então, nesse momento, sem disfarces, romperam soluções do peito da tancareira. Espaçados, pungentes, envergonhados. Manuel quis-lhe pedir que os contivesse, mas estrangulara-se-lhe a voz. E sentiu que perdia qualquer coisa de inestimável que jamais poderia ser substituida. Remou com mais vigor na penosa necessidade de escapar àquela cena. O inverno soprava da China uns resquícios do seu vento gelado. Mas, de novo, ninguém deu por ele. E os soluços continuavam. Espaçados, pungentes, envergonhados.

O marinheiro não subiu imediatamente para a lancha. Já soara o segundo apito para a largada. Ficaram a olhar para a filha adormecida, ambos lutando para balbuciar algumas palavras. Ela feia, sucumbida, a conter em vão os soluços, para implorar que voltasse para tirá-la do rio que era a sua prisão. Ele, para inutilmente prometer os mais impossiveis compromissos, e rogar-lhe que fosse boa rapariga.

Quando o apito estrugiu mais uma vez. Manuel estendeu os braços para a tancareira humilde. A-Chan mirou-o num instante e depois, suavemente, entregou-lhe a filha pequenina, murmurando numa derradeira solicitude maternal.

- Cuidadinho... cuidadinho... (SENNA FERNANDES, 2008, p. 12).

A cena final reflete a pungente despedida de dois seres tão diferentes, unidos pela ternura e pela filha mestiça, Mei-Lai, cujos traços europeus 
proporcionariam para ela uma existência imersa em estigma social na sociedade macaense.

\section{Considerações finais}

Na narrativa, "A-Chan, a tancareira", escrita por Senna Fernandes, quando tinha 27 anos de idade, o autor evoca o sofrimento da população durante a Guerra no Pacifico, apesar de Portugal, que administrava a península e ilhas adjacentes, ter sido declarado neutro no conflito mundial. No início da invasão estrangeira, em 1942, Henrique tinha 19 anos de idade, sendo, portanto, uma testemunha ocular dos trágicos eventos.

A condição de mestiça de Mei-Lai, a filha de um português e de uma chinesa, nascida durante a guerra, é um dos principais temas da narrativa que tem um caráter histórico, social e cultural. 0 escritor apresenta uma capital colonial, dividida entre a cidade chinesa e a cidade portuguesa, e denuncia o tráfico de meninas, vendidas pelos pais, em contradição à política lusa, mas que era usual na China, continental e insular. Ao mesmo tempo, ele revela à leitora e ao leitor ocidental, uma prática comum naquela região: o transporte de pessoas e mercadorias por tancareiras, uma profissão que exige uma intensa força muscular e que cria um espaço feminino de poder que permite liberdade e segurança social e financeira para aquelas mulheres.

Henrique de Senna Fernandes humaniza o marinheiro português, considerado por muitos como invasor, no contexto do processo de expansão maritima de Portugal, no Oriente. Manuel era sensivel, solitário e, por causa de sua profissão, sentia-se um inadaptado na vida em terra firme. Por ser de hierarquia baixa na Marinha, um homem como ele não teria condições financeiras, a longo prazo, de constituir uma família legítima.

O escritor dá voz a uma jovem tancareira, e nome, A-Chan, bem como à sua filha, Mei- Lai, e eterniza em sua narrativa a árdua vida feminina na pequena embarcação: "Guiava seguramente o tancar nos errores do rio, escapulia-se das correntes e da vizinhança minaz doutros barcos com ligeireza inusitada" (SENNA FERNANDES, 2008, p. 1).

No presente estudo "Mei-Lai, a menina mestiça do Porto Interior de Macau em 'A-chan, a tanca- reira' (1950), de Henrique de Senna Fernandes (1923-2010)", o destaque foi para os traços europeus da criança, olhos claros e cabelos louros, que criariam para ela a condição de uma estigmatizada (Goffmann) em uma sociedade taoísta, na qual seria, talvez, uma cortesã. Nesse conto, o escritor macaense presta um tributo às inúmeras crianças, anônimas e esquecidas, nascidas de relações entre portugueses e estrangeiras, não somente em Macau, mas também no Japão, em Goa, Malaca e outras regiões asiáticas.

\section{Referências}

BATALHA, Graciete N. Glossário do Dialecto Macaense. Coimbra: Instituto de Estudos românicos, 1977.

BOTAS, Jorge. Lancha-Canhoneira "Macau". In: MACAU ANTIGO. Macau, 10 ago. 2013. Disponivel em: http:// macauantigo.blogspot.com/2013/08/lancha-canhoneira-macau.html. Acesso em: 23 ago. 2020.

CABRAL, João de Pina; LOURENÇO, Nélson. O Macau Bambu: sobre a identidade étnica macaense e a sucessão das gerações. Administração, v. 6, n. 2, p. 523-558, 1993.

CASTRO, Isabel. Henrique de Senna Fernandes: O miúdo que escrevia romances de amor. In: Tai Chung Pou Domingo. Macau, 30 set. 2007. Disponivel em: http:// taichungpou.blogspot.com/2007/og/henrique-de-senna-fernandes-os.html. Acesso em: 23 ago. 2020.

ESPADINHA, Maria Antónia N. Elogio acadêmico do Doutor Henrique Rodrigues de Senna Fernandes. Macau, 2008. Disponivel em: https://www.um.edu.mo/ honorary/2008/2008_hc_citation_Dr_HRSFernandes. pdf. Acesso em: 23 ago. 2020.

ESTÁCIO, António. Na peugada de Henrique R. de Sena Fernandes. [S. I.], 2010. Disponivel em: https://docplayer. com.br/72149458-Na-peugada-de-henrique-r-de-sena-fernandes.html. Acesso em: 23 ago. 2020.

GOFFMAN, Erving. Estigma: Notas sobre a manipulação deteriorada. Tradução de Mathias Lambert. 4. ed. Rio de Janeiro: Guanabara Koogan, 1988.

HISTÓRIA DE MACAU. In: WIKIPÉDIA: a enciclopédia livre. [San Francisco, CA: Wikimedia Foundation, 2018]. Disponivel em: https://pt.wikipedia.org/wiki/Hist\%C3\%B3ria_de_Macau. Acesso em: 23 ago. 2020.

LUGARINHO, Mário César. Violência e interpretação, leituras da História de Macau. ABRIL: Revista do NEPA/ UFF, Niterói, v. 10, p. 37-48, jan./jun. 2018.

MACAU na II Guerra Mundial E As Histórias De Ocupação. In: Blog Crônicas Macaenses. [S. I.], 23 jul. 2014. Disponivel em: https://cronicasmacaenses.com/2014/07/23/ macau-na-ii-guerra-mundial-e-as-historias-de-ocupacao-complemento-texto-completo. Acesso em: 23 ago. 2020. 
OLIVEIRA, Celina Veiga de. O Conto na obra de Henrique de Senna Fernandes. Administração, v. XXIV, n. 93. p. 853-859, 2011. Disponivel em: file:///C:/Users/ ACER/Downloads/08-Conto\%20obra_Celina\%20Veiga(853-860)\%20(1).pdf. Acesso em: 23 ago. 2020.

RANGEL, Alexandra S. de Senna Fernandes H. Filhos da Terra: A comunidade macaense, ontem e hoje. Dissertação, 2010 (Mestrado em Ciências da CulturaEspecialização em Comunicação e Cultura, Faculdade de Letras, Universidade de Lisboa, Lisboa. Disponivel em: ulflo81900_tm.pdf. Acesso em: 19 out. 2021.

RANGEL, Jorge A. H. Macau no ano a guerra do Pacífico- Porto de abrigo ameaçado. In: Jtm. [S. I.], 4 maio 2020. Disponivel em: https://jtm.com.mo/opiniao/ macau-nos-anos-da-guerra-pacifico-porto-de-abrigo-ameacado. Acesso em: 19 out. 2021.

SEABRA, Leonor D.; MANSO, Maria de Deus B. Escravatura, concubinagem e casamento em Macau: séculos XVI-XVIII. Afro-Asia, Salvador, n. 49, p. 105-133, 2014.

SENNA FERNANDES, Henrique de. A- Chan, a Tancareira. In: SENNA FERNANDES, Henrique de. Nam van: contos de Macau. Rio de Janeiro: Gryphus; Lisboa, Portugal: Direcção Geral do Livro e das Bibliotecas, 2008. p. 1-12

SIMAS, Mònica. Identidade e memória no espaço literário de lingua portuguesa em Macau. In: GARMES, Hélder (org.). Oriente, engenho e arte: imprensa e literatura de lingua portuguesa em Goa, Macau e Timor Leste. São Paulo: Alameda, 2004. p. 134-189.

SIYUAN, Ma. Um olhar português sobre a China: As relações luso-chinesas nas obras de alguns autores portugueses. 2015. Dissertação (Mestrado em Linguas, Literaturas e Culturas) - Departamento de Lingua e Culturas da Universidade de Aveiro, Aveiro, Portugal. Disponivel em: https://ria.ua.pt/bitstream/10773/14618/1/ Tese.pdf. Acesso em: 23 ago. 2020

YANG, A. Alexander Chung Yuan. O comércio de Cantão (1720-1979). Revista de História, v. 54, n. 107, p. 31-44, 1976. Disponivel em: https://www.revistas.usp.br/revhistoria/article/view/78547. Acesso em: 23 ago. 2020.

\section{Denise Rocha}

Doutora em Literatura e Vida Social pela Universidade Estadual Paulista (UNESP), em Assis, SP, Brasil; Mestre em Artes (Magister Artium) em História e Ciências da Literatura pela Ruprechts-Karl-Universität, em Heidelberg, Alemanha; Professora do PPG Letras da Universidade Federal do Ceará, em Fortaleza, CE, Brasil.

\section{Endereço para correspondência}

Denise Rocha

Universidade Federal do Ceará

Av. da Universidade, 2683 - Área 1, térreo

Benfica, 60020181

Fortaleza, CE, Brasil

Os textos deste artigo foram revisados pela Poá Comunicação e submetidos para validação da autora antes da publicação. 